\title{
Clinical Trial Central Laboratory Certification Document
}

National Cancer Institute

\section{Source}

National Cancer Institute. Clinical Trial Central Laboratory Certification Document. NCI

Thesaurus. Code C115645.

Records detailing the certification by an authorized accrediting body of a central laboratory indicating their competence to participate in a given clinical trial. 